\title{
Impact of a long-term tobacco-free policy at a comprehensive cancer center: a series of cross-sectional surveys
}

\author{
Cristina Martínez ${ }^{1,2,3^{*}}$, Marcela Fu²,2,3, Jose María Martínez-Sánchez ${ }^{1,2,4}$, Laura Antón ${ }^{1,2}$, Paz Fernández \\ Montse Ballbè ${ }^{1,2,6,7}$, Ana Andrés ${ }^{1,2,8}$, Anna Riccobene ${ }^{1,2}$, Xisca Sureda ${ }^{1,2,7}$, Albert Gallart ${ }^{3}$ and Esteve Fernández ${ }^{1,2,7}$
}

\begin{abstract}
Background: Spain has passed two smoke-free laws in the last years. In 2005, the law banned smoking in indoor places, and in 2010 the ban was extended to outdoor areas of certain premises such as hospitals. This study assesses the impact of smoking consumption among hospital workers at a comprehensive cancer center after the passage of two national smoke-free laws.

Methods: Six cross-sectional surveys were conducted among a representative sample of hospital workers at a comprehensive cancer center in Barcelona (2001-2012) using a standardized questionnaire. Logistic regression was used to compare differences in the odds of smoking after the laws took effect (baseline vs. $1^{\text {st }}$ law; $2^{\text {nd }}$ law vs. $1^{\text {st }}$ law).

Results: Baseline smoking prevalence was $33.1 \%$. After passage of the $1^{\text {st }}$ and $2^{\text {nd }}$ laws, prevalence decreased, respectively, to $30.5 \%$ and $22.2 \%$ ( $p$ for trend $=0.005$ ). Prevalence ratios $(P R$ ) indicated a significant decrease in overall smoking after the $2^{\text {nd }}$ law $(P R=0.65,95 \% C l=0.47-0-89)$. Smoking dropped in all professional groups, more prominently among those $\geq 35$ years old, doctors, and women. Observed trends over the time included an increase in occasional smokers, a rise in abstinence during working hours but an increase in smoking dependence, and an increase in the employees' overall support for the smoke-free hospital project.

Conclusions: A long-term tobacco control project combined with two smoke-free national laws reduced smoking rates among health workers and increased their support for tobacco control policies. The decrease was more significant after the passage of the outdoor smoke-free ban.
\end{abstract}

Keywords: Hospital, Smoke-free policies, Health care providers, Smoking, Ban

\section{Background}

Smoke-free policies are one of the most effective measures recommended by the World Health Organization Framework Convention on Tobacco Control (WHO FCTC) to control the tobacco epidemic [1,2]. Smoking bans can be implemented by private organizations, accrediting agencies or boards, and local, state, or federal

\footnotetext{
* Correspondence: cmartinez@iconcologia.net

'Tobacco Control Unit, Cancer Control and Prevention Programme, Institut Català d'Oncologia-ICO, Av. Granvia de L'Hospitalet 199-203, 08908 L'Hospitalet de Llobregat, Barcelona, Spain

${ }^{2}$ Cancer Control and Prevention Group, Institut d'Investigació Biomèdica de Bellvitge-IDIBELL, Av. Granvia de L'Hospitalet 199-203, 08908 L'Hospitalet de Llobregat, Barcelona, Spain

Full list of author information is available at the end of the article
}

governments through legislation [3,4]. Both governments and health organizations play leading active roles in tobacco control, sharing responsibility in providing primary healthcare, educating the community about tobaccorelated issues, and assuring that public environments are healthy $[5,6]$.

Since the approval of the WHO FCTC, more than 120 countries $[7,8]$ and numerous health organizations have strengthened their smoke-free policies [9-12]. By means of these smoking bans, workers at hospitals that have either governmental or non-governmental smoke-free policies in place may benefit more than the general population from such policies. The benefits of smokefree policies in health care services include: (a) decreased 
exposure to second-hand smoke (SHS) [13,14]; (b) increased number of quit attempts and slightly reduced smoking consumption prevalence [15,16]; and (c) a greater involvement in conducting tobacco prevention and cessation activities [17-20].

In 2005, Spain passed its first comprehensive smokefree law, which banned smoking in indoor public places, workplaces, and health care services, except in hospitality venues [21]. In 2010, that law was amended providing: (1) smoke-free indoors for the hospitality sector (bars and restaurants) without exceptions, and (2) Smoke-free outdoors in some public areas including hospital grounds, educational campuses, and playgrounds [22]. However, some hospitals had already implemented their own regulations to prohibit smoking indoors before the first national law was enacted [23,24]. Since 2002, the Catalan Institute of Oncology (ICO), a comprehensive cancer center in Barcelona, has developed several tobacco control policies by following the guidelines from the ENSH-Global Network for Tobacco-Free Health care Services (www.ensh.eu) $[15,25]$. Throughout the 12 years of the hospital tobacco control project, several policies recommended in the ENSH model have been implemented, including: awareness campaigns on the hazards of SHS, smoke-free policies to protect people from SHS exposure, tobacco cessation services (including psychological support and pharmacotherapy if needed), and training courses for professionals, promotion activities, and evaluation efforts. These policies have been regularly monitored through diverse methods including smoking prevalence surveys, self-audit questionnaires, and observational inspections $[10,15,24,26,27]$.

Although previous studies have monitored the psychosocial and behavioral effects of tobacco control policies at the hospital level [15,28-30], those studies have not evaluated the impact of long-term institutional tobacco-free policies combined with the national smoke-free bans.

Given this context, the aim of this paper is to describe the impact of a 12-year tobacco control project (20002012) implemented in a comprehensive cancer center in combination with two national smoking bans (passed in 2005 and 2010). We describe trends in smoking consumption, attitudes, and behaviors among hospital workers at baseline (before passage of the 2 laws), after the $1^{\text {st }}$ law (which banned smoking indoors), and after the $2^{\text {nd }}$ law (which banned smoking on hospital grounds).

\section{Methods}

\section{Design, procedure and sample}

Six surveys were carried out among a representative sample of the employees of the Catalan Institute of Oncology from 2001 to 2012. According to the introduction of the national smoke-free bans, we defined the following evaluation periods: Baseline, before the $1^{\text {st }}$ indoor smoke-free law: surveys in 2001, 2002 and 2004; after the $1^{\text {st }}$ smokefree law, which banned smoking indoors: surveys in 2006 and 2009; after the $2^{\text {nd }}$ smoke-free law, which additionally banned smoking on hospital grounds: survey in 2012.

All surveys were conducted in the spring (from April to June) to avoid holiday seasons. Sample size estimation took into account the smoking prevalence among health care professionals in Catalonia, which was approximately 5 percentage points lower than prevalence in the general population [31]. The sample size was calculated using Statcalc in Epilnfo, version 6.0.4 (Centers for Disease Control and Prevention, Atlanta, US). Detailed sampling and data collection procedures have been previously reported [15]. However, in brief, a random sample of workers, based on age and sex group, was drawn from the Human Resources department updated files.

Research assistants located the index worker and provided him/her with the self-administered anonymous questionnaire contained in an envelope which the worker could use to return the questionnaire anonymously to maintain confidentiality. Participants absent from work on the interview days were contacted by the interviewers a maximum of four times at their work place. If subjects were not located, other subjects from the same group of age and sex were randomly selected as substitutes: substitution accounted for less than $12 \%$ of the corresponding sample in each of the six surveys.

\section{Questionnaire and variables}

The survey instrument was developed by the experts' working group from the ENSH-Global Network for Tobacco-free Hospitals (www.ensh.eu) [15] and adapted by the researchers. The questionnaires used in 2001 and 2002 were identical while the surveys used from 2004 to 2012 were shorter than the original version but maintained the following core variables: social and demographic data, profession, smoking status, and attitudes towards active and passive smoking.

The dependent variable was the prevalence of smoking. Subjects were classified according to smoking status as follows: daily smokers (currently smoking at least 1 cigarette/ day), occasional smokers (currently smoking $<1$ cigarette/ day), former smokers (not smoking for $\geq 6$ months) [32], and never-smokers. We computed the prevalence (\%) of smoking, including daily and occasional smokers. Among daily smokers, tobacco dependence was evaluated in terms of the number of cigarettes per day $(<10,10-20$, and $>20)$ and the time to the first cigarette after waking up $(\leq 30$ and $>30$ minutes). For all smokers, we collected additional information such as their concern about how smoking affected their own and others health, previous attempts to quit in the last year (yes, no), readiness to quit according to the stages of change model (pre-contemplation, contemplation, preparation) [33] -we considered "ready to quit" all 
responders in the contemplation and preparation stages-, readiness to set a date to quit at the moment of the interview (yes, no), previous consultation with a health professional to quit smoking (yes, no), and refraining from smoking in all areas of the hospital grounds (yes, no).

The main independent variables were sex, age, and profession, with the age variable divided into two separate categories (mean age $<35$ years or $\geq 35$ years). Professional categories included doctors, nurses, administrative employees, and other hospital workers included mainly technicians, statisticians, researchers, and a very small number of workers who are phycologists (one in our organization), nutritionists (one in our organization). For some analyses, we categorized them as health care providers (nurses and doctors) and non-health care providers (administrative employees and others).

Finally, we surveyed all hospital workers to assess their support for the 'Hospital Tobacco Control Project', their agreement with the exemplary role that some groups should set (health care providers, teachers, and parents), and their opinion regarding the importance of raising taxes to effectively reduce tobacco consumption. Each of these questions had two response options (agree or disagree).

\section{Ethical considerations}

Each survey administered was previously approved by the Institution Ethical Board of the Hospital Universitari de Bellvitge and participants gave oral consent to participate.

\section{Statistical analysis}

The prevalence (\%) of daily and occasional smokers, former smokers, and never-smokers of cigarettes, cigars or pipes, and $95 \%$ confidence intervals (CI) were computed. $99.6 \%$ of smokers were cigarette users. Smokers' patterns of tobacco consumption were characterized in terms of tobacco dependence (number of cigarettes per day and time to first cigarette), readiness to quit, previous quit attempts, and previous consultation with a health professional to quit. To determine the trend over the time we computed the $\mathrm{p}$-value for the linear trend for the target variables.

The impact of the two laws was assessed by fitting logbinominal regression models to obtain the prevalence ratio (PR) and 95\% CIs for smoking after the $1^{\text {st }}$ law (surveys from 2006 and 2009) and after the $2^{\text {nd }}$ law (results from 2012) compared to baseline values (from surveys carried out in 2001, 2002, and 2004). We adjusted the models for sex, age, and profession, when necessary. All procedures were implemented using SPSS 18.0.

\section{Results}

\section{Socio-demographic data}

Approximately 200 workers were interviewed in each cross-sectional survey. Over the study period, the femaleto-male ratio remained stable (75\% females). However, the distribution of age changed, with the proportion of workers aged $\geq 35$ years increasing during the study period. The professional status distribution also changed, with nurses accounting for $44.8 \%$ of participants at baseline to $34.9 \%$ after the passage of the $2^{\text {nd }}$ law; in contrast, representation of the "other professionals" increased from $21.4 \%$ at baseline to $26.2 \%$ after the $2^{\text {nd }}$ law (Table 1).

Table 1 Demographic participants' characteristics at baseline, after passage of the 1st and 2nd smoke-free laws

\begin{tabular}{|c|c|c|c|c|c|c|c|}
\hline & \multirow{2}{*}{\multicolumn{2}{|c|}{$\begin{array}{c}\text { Baseline: 2001-2002-2004 } \\
(n=580)\end{array}$}} & \multirow{2}{*}{\multicolumn{2}{|c|}{$\begin{array}{c}\text { After } 1^{\text {st }} \text { law: } 2006-2009 \\
(n=462)\end{array}$}} & \multirow{2}{*}{\multicolumn{2}{|c|}{$\begin{array}{c}\text { After } 2^{\text {nd }} \text { law: } 2012 \\
(n=221)\end{array}$}} & \multirow[t]{3}{*}{$p$ for trend } \\
\hline & & & & & & & \\
\hline & $\mathrm{n}$ & $\%$ & $\mathrm{n}$ & $\%$ & $\%$ & $\%$ & \\
\hline \multicolumn{8}{|l|}{ Sex } \\
\hline Men & 150 & 25.9 & 111 & 24.0 & 52.0 & 23.5 & \multirow[t]{2}{*}{0.429} \\
\hline Women & 430 & 74.1 & 351 & 76.0 & 169.0 & 76.5 & \\
\hline \multicolumn{8}{|l|}{ Age group (years) } \\
\hline $18-24$ & 28 & 4.8 & 25 & 5.5 & 7.0 & 3.2 & \multirow[t]{5}{*}{$<0.001$} \\
\hline $25-34$ & 276 & 47.6 & 184 & 39.8 & 61.0 & 27.6 & \\
\hline $35-44$ & 191 & 32.9 & 173 & 37.4 & 95.0 & 43.0 & \\
\hline $44-55$ & 63 & 10.9 & 60 & 13.0 & 46.0 & 20.8 & \\
\hline$>55$ & 22 & 3.8 & 20 & 4.3 & 12.0 & 5.4 & \\
\hline \multicolumn{8}{|l|}{ Profession group } \\
\hline Doctors & 104 & 17.9 & 81 & 17.5 & 41.0 & 18.6 & \multirow[t]{4}{*}{0.060} \\
\hline Nurses & 260 & 44.8 & 186 & 40.3 & 77.0 & 34.8 & \\
\hline Administrative employees & 92 & 15.9 & 66 & 14.3 & 45.0 & 20.4 & \\
\hline Others & 124 & 21.4 & 129 & 27.9 & 58.0 & 26.2 & \\
\hline
\end{tabular}




\section{Smoking status}

At baseline, before passage of the national smoking laws, 33.1\% (95\% CI 29.3-36.9) of hospital workers were smokers; however, after the implementation of the $1^{\text {st }}$ smoke-free law -which banned smoking indoors- the prevalence decreased to $30.5 \%$ (95\% CI 26.3-34.7), and after the implementation of the $2^{\text {nd }}$ law - which extended the smoking ban to outdoors- prevalence decreased to $22.2 \%$ (95\% CI 16.7-27.6), with a statistically significant trend $(\mathrm{p}=0.005$; Table 2). After adjustment, the model confirms a lower prevalence of smokers after the $2^{\text {nd }}$ law $(P R=0.65,95 \%$ CI: 0.47-0.89) (Table 2). Figure 1 shows the decline in tobacco consumption after the passage of the two laws.

By sex, the prevalence of smoking decreased progressively in both men and women over the three periods. Among men, smoking prevalence dropped from $27.3 \%$ at baseline to $19.2 \%$ after passage of the $2^{\text {nd }}$ law. Among women, smoking prevalence dropped from $35.1 \%$ at baseline to $23.1 \%$ after the $2^{\text {nd }}$ law, with an even greater reduction in prevalence after the $2^{\text {nd }}$ law compared to the $1^{\text {st }}$ law (Table 2 ). By age, workers $\geq 35$ years old reduced their smoking prevalence after each of the two laws, with greater decrease observed after the $2^{\text {nd }}$ law (PR after $1^{\text {st }}$ law $=0.65,95 \%$ CI: 0.47-0.91; PR after $2^{\text {nd }}$ law $=0.42$, 95\% CI: 0.27-0.67). Among the oldest workers ( $\geq 35$ years old), the increased percentage of former smokers occurred mainly after the $1^{\text {st }}$ law $(P R=1.48$, 95\% CI: $1.09-2.02)$. The youngest workers (<35 years old) maintained a stable smoking consumption prevalence $(\sim 35 \%)$ before and after passage of the two smokefree laws (Table 2).

Smoking prevalence decreased in all hospital worker groups during the study period. After the $2^{\text {nd }}$ law, doctors had the lowest prevalence (15.0\%) while administrative staff had the highest (33.3\%), with adjusted PRs of 0.20 (95\%CI: 0.05-0.87) and 0.78 (95\%CI: 0.42-1.46), respectively to baseline (Table 2).

\section{Smoking pattern}

Table 3 shows the smoking pattern through the three evaluation periods. We observed that occasional smokers increased twofold, from $12.1 \%$ (95\% CI: 7.5-16.7) at baseline to $24.5 \%$ (95\% CI: $12.5-36.5)$ after passage of the $2^{\text {nd }}$ law.

No clear trend was observed in the number of daily cigarettes and time to first cigarette, with oscillations during the three study periods. Nevertheless, after both smoke-free laws were passed, the percentage of smokers who smoked 10 to 20 cigarettes per day increased, and those that smoked their first cigarette $\leq 30$ minutes after waking up increased from $3.6 \%$ at baseline to $39.1 \%$ after the $2^{\text {nd }}$ law (p for trend $<0.001$ ) (Table 3 ).

\section{Smokers' concern about tobacco harmful effects}

Overall, smokers' concern about the health of others decreased from $66.0 \%$ at baseline to $48.9 \%$ after the second

Table 2 Smoking status prevalence by selected independent variables at baseline, after passage of the $1^{\text {st }}$ and $2^{\text {nd }}$ smoke-free laws

\begin{tabular}{|c|c|c|c|c|c|c|c|}
\hline & \multirow{2}{*}{\multicolumn{2}{|c|}{$\begin{array}{c}\text { Baseline 2001-2002-2004 } \\
(n=580)\end{array}$}} & \multirow{2}{*}{\multicolumn{2}{|c|}{$\begin{array}{c}\text { After } 1^{\text {st }} \text { law 2006-2009 } \\
(n=462)\end{array}$}} & \multirow{2}{*}{\multicolumn{2}{|c|}{$\begin{array}{c}\text { After } 2^{\text {nd }} \text { law } 2012 \\
(n=221)\end{array}$}} & \multirow[t]{3}{*}{$\mathrm{p}$ for trend } \\
\hline & & & & & & & \\
\hline & $\%$ & PR (Ref) & $\%$ & PR $(95 \% \mathrm{Cl})^{\mathrm{a}}$ & $\%$ & PR $(95 \% \mathrm{Cl})^{\mathrm{a}}$ & \\
\hline Never-smokers & 42.9 & 1 & 41.6 & $0.99(0.82-1.20)$ & 49.7 & $1.28(1.01-1.62)$ & 0.118 \\
\hline Former smokers & 24.7 & 1 & 27.9 & $1.18(0.99-1.46)$ & 28.1 & $0.69(0.82-1.50)$ & 0.232 \\
\hline Current smokers $^{\mathbf{b}}$ & 33.1 & 1 & 30.5 & $0.91(0.73-1.13)$ & 22.2 & $0.65(0.47-0.89)$ & 0.005 \\
\hline \multicolumn{8}{|c|}{ Smoking prevalence by selected variables } \\
\hline \multicolumn{8}{|l|}{ Sex } \\
\hline Men & 27.3 & 1 & 22.5 & $0.77(0.46-1.30)$ & 19.2 & $0.59(0.28-1.22)$ & 0.200 \\
\hline Women & 35.1 & 1 & 33.0 & $0.94(0.74-1.21)$ & 23.1 & $0.65(0.46-0.94)$ & 0.009 \\
\hline \multicolumn{8}{|l|}{ Age group (years) } \\
\hline$<35$ & 34.2 & 1 & 39.2 & $1.18(0.87-1.58)$ & 35.3 & $1.01(0.64-1.59)$ & 0.507 \\
\hline$\geq 35$ & 31.9 & 1 & 23.3 & $0.65(0.47-0.91)$ & 16.3 & $0.42(0.27-0.67)$ & 0.000 \\
\hline \multicolumn{8}{|l|}{ Professional group } \\
\hline Doctors & 22.1 & 1 & 17.3 & $0.72(0.37-1.41)$ & 15.0 & $0.20(0.05-0.87)$ & 0.018 \\
\hline Nurses & 31.5 & 1 & 31.7 & $1.08(0.77-1.52)$ & 24.7 & $0.82(0.49-1.38)$ & 0.357 \\
\hline Administrative staff & 41.3 & 1 & 27.3 & $0.61(0.34-1.08)$ & 33.3 & $0.78(0.42-1.46)$ & 0.222 \\
\hline Others & 39.5 & 1 & 38.8 & $0.95(0.66-1.47)$ & 22.4 & $0.54(0.29-1.01)$ & 0.050 \\
\hline
\end{tabular}

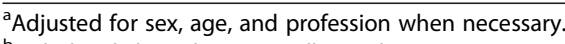

bincludes daily and occasionally smokers.

PR: prevalence ratio obtained from a log-binomial regression model adjusted for sex, age group, and profession group when necessary. 


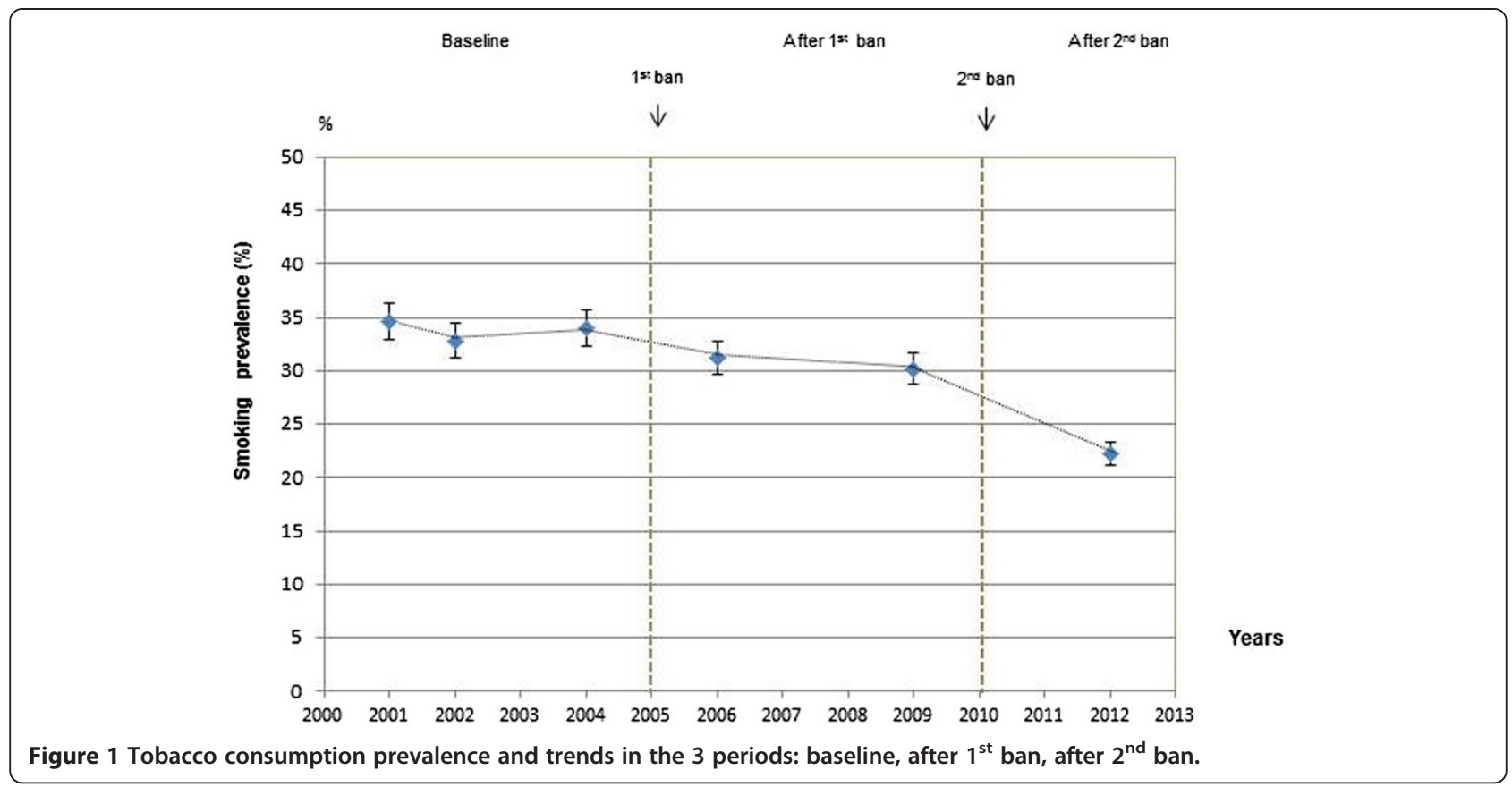

law ( $\mathrm{p}$ for trend $=0.002$ ). However, their concern for their own health remained stable over the 12-year period (Table 3).

\section{Attempts to quit smoking}

At baseline, $57.4 \%$ of smokers reported having made a serious attempt to quit; after passage of the $2^{\text {nd }}$ law (Table 3), this percentage had increased to $72.3 \%$. Over the study period the percentage of smokers who reported consulting a health professional to quit increased four-fold [from $10.1 \%$ to $40.7 \%$ to $65.3 \%$ respectively, at baseline, after the $1^{\text {st }}$ law, and after the $2^{\text {nd }}$ law; $p$ for trend $<0.001]$. After the passage of the two smoke-free laws, the decrease in the percentage of smokers who considered themselves ready to quit was quite steep [from $60.3 \%$ at baseline to $11.5 \%$ after the $2^{\text {nd }}$ law ( $\mathrm{p}$ for trend $<0.001)$ ]; similarly, the proportion of subjects expressing a desire to set a quit day also decreased substantially [from $36.5 \%$ at baseline to $20.4 \%$ after the $2^{\text {nd }}$ law ( $p$ for trend $=0.036$ )]. The percentage of smokers who refrain from smoking during working hours increased after each of the laws (from $14.1 \%$ at baseline to $34.0 \%$ after the $2^{\text {nd }}$ law, $p$ for trend $<0.001$ ).

\section{Attitudes toward smoking and tobacco control policies}

The majority of hospital workers agreed with the tobacco control policies implemented at the hospital, with a large increase in support following passage of the $2^{\text {nd }}$ law ( $\mathrm{p}$ for trend <0.001) (Table 4). Nevertheless, when we compared health care providers (HCP) to non-HCP, we observed a significant trend only in the former group: $59 \%$ of HCP agreed with the tobacco control policies at baseline and $80.5 \%$ agreed with them after the $2^{\text {nd }}$ law ( $\mathrm{p}=0.000)$ (data not shown).

Agreement about the role of health professionals in setting a good example increased slightly among all workers over the study period (from $53.8 \%$ at baseline to $61.4 \%$ after the $2^{\text {nd }}$ law, $p$ for trend $=0.009$ ); however, after the $2^{\text {nd }}$ law, the agreement of smokers with this statement was 39 percentage points lower than the mean score of the whole group of workers (Table 4). HCP presented higher support $(66.1 \%)$ to this statement after the $2^{\text {nd }}$ law if compared with non-HCP $(33.9 \%$, p < 0.05\%)).

Finally, half of hospital workers agreed that taxes should be raised to effectively control tobacco consumption, without changes before and after implementation of the two smoke-free laws. Support for taxes among smokers was lower $(37.0 \%)$ than the entire group of workers $(52.8 \%$; $\mathrm{p}<0.05 \%$ ) (Table 4).

\section{Discussion}

The present study assesses, for the first time, the impact of a long-term tobacco control project in combination with two national smoke-free laws. Findings indicate a significant smoking reduction (mainly after passing the $2^{\text {nd }}$ law) and important changes in smoking patterns, including an increase in the proportion of occasional smokers, a rise in smoking abstinence during working hours, and an increase in support for the hospital tobacco control policies in the whole study population, particularly in nonsmokers and health care providers. As previous studies indicate, the more restrictive the smoke-free policies, the greater the effects on smoking behavior [4,34-36]. At baseline, smoking prevalence among hospital workers was 
Table 3 Smoking pattern among smokers before law, after passage of the 1st and 2nd smoke-free

\begin{tabular}{|c|c|c|c|c|c|c|c|}
\hline & \multicolumn{2}{|c|}{ Baseline $(n=190)$} & \multicolumn{2}{|c|}{ After $1^{\text {st }}$ law $(n=138)$} & \multicolumn{2}{|c|}{ After $2^{\text {nd }}$ law $(n=49)$} & \multirow[t]{2}{*}{$p$ for trenc } \\
\hline & $\%$ & $95 \% \mathrm{Cl}$ & $\%$ & $95 \% \mathrm{Cl}$ & $\%$ & $95 \% \mathrm{Cl}$ & \\
\hline \multicolumn{8}{|l|}{ Type of consumption } \\
\hline Daily smokers & 87.90 & $(83.3-92.5)$ & 79.0 & $(72.2-85.8)$ & 75.5 & $(63.3-87.5)$ & 0.012 \\
\hline Occasional smokers & 12.10 & $(7.5-16.7)$ & 21.0 & $(14.2-27.8)$ & 24.5 & $(12.5-36.5)$ & \\
\hline \multicolumn{8}{|l|}{ Tobacco dependence } \\
\hline \multicolumn{8}{|c|}{ Number of cigarettes per day } \\
\hline$<10$ cigarettes & 50.6 & $(43.5-57.7)$ & 45.9 & $(37.5-54.2)$ & 40.5 & $(26.7-54.2)$ & 0.226 \\
\hline 10-20 cigarettes & 43.8 & $(36.7-50.8)$ & 40.5 & $(32.3-48.7)$ & 59.5 & $(45.7-73.2)$ & 0.710 \\
\hline$>20$ cigarettes & 5.7 & $(2.4-8.9)$ & 13.5 & $(7.8-19.2)$ & 0.0 & - & 0.827 \\
\hline \multicolumn{8}{|c|}{ First cigarette after awaking } \\
\hline$\leq 30$ minutes & 3.6 & $(1.1-6.6)$ & 6.0 & $(2.0-9.9)$ & 39.1 & $(25.4-52.7)$ & $<0.001$ \\
\hline$>30$ minutes & 96.4 & $(93.7-99.0)$ & 82.6 & $(76.3-88.9)$ & 60.9 & $(47.2-74.5)$ & \\
\hline \multicolumn{8}{|l|}{ Willingness to quit } \\
\hline \multicolumn{8}{|c|}{ Concerned about tobacco use effects } \\
\hline On their own health & 69.7 & $(63.2-76.2)$ & 71.7 & $(64.2-79.2)$ & 62.5 & $(48.9-76.0)$ & 0.594 \\
\hline On others health & 66.0 & $(59.3-72.7)$ & 46.2 & $(37.9-54.5)$ & 48.9 & $(34.9-62.9)$ & 0.002 \\
\hline \multicolumn{8}{|c|}{ Previous quit attempts in the last year } \\
\hline Yes & 57.4 & $(50.4-64.4)$ & 56.5 & $(48.2-64.7)$ & 72.3 & $(59.7-84.5)$ & 0.163 \\
\hline \multicolumn{8}{|l|}{ Readiness to quit } \\
\hline Yes & 60.3 & $(56.1-69.8)$ & 28.20 & $(20.8-35.7)$ & 11.5 & $(2.2-19.7)$ & $<0.001$ \\
\hline \multicolumn{8}{|c|}{ Readiness to fix a data to quit } \\
\hline Yes & 36.5 & $(29.65-43.3)$ & 31.40 & $(23.3-38.7)$ & 20.4 & $(12.1-35.6)$ & 0.036 \\
\hline \multicolumn{8}{|c|}{ Consulted a professional to quit } \\
\hline Yes & 10.1 & $(5.7-14.3)$ & 40.7 & $(32.8-49.2)$ & 65.3 & $(56.4-82.2)$ & $<0.001$ \\
\hline \multicolumn{8}{|c|}{ Refrain from smoking in working hours } \\
\hline Yes & 14.1 & $(9.15-19.0)$ & 28.6 & $(21.1-36.1)$ & 34.0 & $(20.7-47.3)$ & 0.001 \\
\hline
\end{tabular}

similar to prevalence in the general population at that time (33.1\% versus $32.1 \%$, respectively) [37]. After the implementation of the $1^{\text {st }}$ law, prevalence remained similar to the general population $(30.5 \%$ versus $29.4 \%$, respectively) [31]; however, after implementation of the $2^{\text {nd }}$ law, smoking prevalence among hospital workers decreased sharply in comparison to the general population (22.2\% versus 29.5\%, respectively) [38]. This gradual decrease suggests an additive effect of the long-term organizational tobacco control policy in conjunction with national policies on hospital workers' behavior.

Decreases in tobacco consumption were observed mainly in hospital workers $\geq 35$ years old, doctors, and women. We hypothesize that the smoke-free legislation has had lower impact on the youngest group ( $<35$ y) because young smokers tend to trivialize the harmful effects of smoking, and in our context there are insufficient initiatives addressed to motivate cessation among young smokers, even for health professionals". It is also remarkable the decrease in smoking rates among women. Although, the hospital has not launched special campaigns addressed to them, we believe that the several cessation training programs addressed to nurses - who are $40 \%$ of our work force and from them $90 \%$ are women- may have had a stronger impact on quitting among this group. In addition, nurses smoking rates have had an appreciable decrease mainly after the passage of the $2^{\text {nd }}$ law.

Health workers are viewed as exemplary professionals by the rest of the society and thus they should be on the frontlines of tobacco control [39]. According to an international review that described smoking consumption among physicians, countries that implemented early tobacco control policies (e.g., the United States, Australia, and the United Kingdom) had a rapid decline in smoking prevalence among physicians, and currently those countries now have the lowest prevalence rates in the world [40]. A similar trend study conducted in Ireland showed also a striking decrease in smoking staff rates but with a stronger occupational gradient than in ours [41]. Our study reveals lower smoking rates among 
Table 4 Agreement with the hospital tobacco control policy and some statements among all workers and smoker workers

\begin{tabular}{|c|c|c|c|c|c|c|c|}
\hline & & & & ban & & ban & $p$ for trend \\
\hline & (All $n=5$ & kers $=192$ ) & (All $n=$ & kers $n=141$ & (All $n=$ & okers $n=49$ ) & \\
\hline & $\%$ & $95 \% \mathrm{Cl}$ & $\%$ & $95 \% \mathrm{Cl}$ & $\%$ & $95 \% \mathrm{Cl}$ & \\
\hline $\begin{array}{l}\text { Agreemen } \\
\text { tobacco c }\end{array}$ & & & & & & & \\
\hline All & 59.9 & $(55.9-63.8)$ & 61.7 & $(65.2-73.8)$ & 76.4 & $(70.8-81.9)$ & $<0.001$ \\
\hline Smokers* & 57.8 & $(50.8-64.7)$ & 53.2 & $(44.8-61.5)$ & 71.4 & $(58.7-84.1)$ & 0.320 \\
\hline $\begin{array}{l}\text { Health pr } \\
\text { an examp }\end{array}$ & $\begin{array}{l}\text { old set } \\
\text { smoke }\end{array}$ & & & & & & \\
\hline All & 53.8 & $(49.7-57.8)$ & 62.8 & $(58.4-67.2)$ & 61.4 & $(72.2-83.2)$ & 0.009 \\
\hline Smokers & 43.8 & $(36.8-50.8)$ & 47.5 & $(39.1-55.8)$ & 22.4 & $(10.7-34.1)$ & 0.068 \\
\hline $\begin{array}{l}\text { Teachers } \\
\text { and do } n\end{array}$ & example & & & & & & \\
\hline All & 56.2 & $(52.3-60.4)$ & 62.6 & $(58.4-67.2)$ & 64.5 & $(58.5-71.1)$ & 0.014 \\
\hline Smokers & 43.2 & $(36.2-50.2)$ & 46.1 & $(37.8-54.4)$ & 30.6 & $(17.7-43.5)$ & 0.303 \\
\hline $\begin{array}{l}\text { Parents } s l \\
\text { do not } s m\end{array}$ & xample an & & & & & & \\
\hline All & 68.8 & $(64.2-71.8)$ & 70.8 & $(66.6-74.9)$ & 77.3 & $(71.2-82.8)$ & 0.027 \\
\hline Smokers & 59.9 & $(52.9-66.8)$ & 59.5 & $(51.3-67.7)$ & 49.0 & $(35.0-62.9)$ & 0.266 \\
\hline $\begin{array}{l}\text { Taxes sho } \\
\text { tobacco c }\end{array}$ & decrease & & & & & & \\
\hline All & 52.8 & $(48.4-56.6)$ & 44.2 & $(65.2-73.8)$ & 57.5 & $(50.89-64.0)$ & 0.875 \\
\hline Smokers & 37.0 & $(30.2-43.8)$ & 39.0 & $(30.9-47.1)$ & 36.7 & $(23.2-50.2)$ & 0.892 \\
\hline
\end{tabular}

oncology nurses than among administrative and general population. However, oncology nurses at our institution still smoke more (by 10 percentage points) than oncology doctors, a finding that is consistent with the situation in other developed countries [42].

In the last decade, smoke-free policies in Europe have become more common in health care services due to the passage of both governmental [8] and non-governmental initiatives [43]. Nevertheless, despite the clear benefits of smoke-free policies [4], the WHO FCTC encourages organizations and governments to do more than just implement restrictions, advocating for the development of a broad tobacco control approach [1]. In this regard, our 'Hospital Tobacco Control Project' has developed a comprehensive tobacco-free model based on the ENSHGlobal Network for Tobacco-free Health Care Services. The ENSH model integrates ten policies in agreement with Article 8, 12, 14, and 21 of the WHO FCTC (Article 8: "smoking bans in public places," Article 12: "consumer information," and Article 14: "access to treatment for quitting smoking," Article 21: "research, surveillance and exchange of information"). The ENSH concept follows an organizational and cultural change model for implementing innovations [44] that has shown that a gradual implementation improves tobacco control policies $[10,45]$.
Many of the other policies recommended in the WHO FCTC have been poorly developed in health care services [46]. For instance, provision of tobacco cessation services (Article 14) is less than optimal [10,47-49] and in many cases the programs offered form part of research studies, with a low likelihood of future sustainability [50,51]. In our context, Catalan hospitals provide tobacco cessation services with the support of the regional government. Our comprehensive cancer center has offered tobacco cessation aid to workers since 2005, including behavioral support and free pharmacological treatment from 2005 to 2008. Afterwards, smoker workers should pay their own pharmacological treatment, and professional tobacco cessation consultation remains out of charge. A study assessing this intervention showed a high probability of abstinence at 6 months follow-up [26]. This result is in line with the substantial decrease in the prevalence of tobacco consumption among our hospital workers after the national bans, as well as the increase in the proportion of smokers who have consulted a health professional for help in quitting tobacco. In addition, the high dependence on cigarettes (i.e., the increase in subjects who have their first cigarette in $\leq 30$ minutes of waking) and the low readiness to quit among our smoker workers is noteworthy, and seems to suggest that some "hardening" of smoking habits 
is occurring in this specific population [52]. Another remarkable point is the substantial increase in the number of occasional smokers in our hospital worker population. However, this finding is in line with other studies that have reported a similar increase in the number of the occasional smokers in countries where tobacco consumption in the overall population is decreasing [53] especially among some role model professions such as health careproviders [54].

Smoking cessation care in hospitals continues to present a challenge in many organizations $[10,47,48]$. Worldwide, the most commonly-identified barriers to smoking cessation efforts include: lack of resources, knowledge, time, and support [55-57]. The deficit in adequate tobacco cessation knowledge starts at the university level. According to a recent study, few health sciences degrees include tobacco cessation training in their curricula [58]. Also, constraints on financial and staffing resources may threaten the suitability of innovative projects [50,51]. As a result neither health professionals nor hospital administrators see providing tobacco cessation services as part of their responsibilities [59]. In our study, hospital workers as a group increased their support for hospital tobacco control policies; however, agreement about the exemplary role of health professionals is still lower than desirable.

This study has limitations that must be considered when interpreting the results. First of all, our study was conducted at a comprehensive cancer center which has taken an active role in as a promoter of the tobacco control hospital model. Therefore, the remarkable decrease in tobacco consumption observed could be higher than in other hospitals. Nevertheless, in Catalonia, similar policies have been implemented at other public hospitals that are members of the Catalan Network for Smokefree Hospitals (90\% of public hospitals are members). This suggests that similar results can be expected at health care organizations/institutions that implement a long-term tobacco control policy that is supported by national smoke-free bans. Another potential limitation of our study is the possibility that cross-sectional surveys that use self-reported smoking status may suffer from information bias related to the increasing denormalization of tobacco consumption and associated attitudes to such consumption over time. However, data collected through cross-sectional surveys provide a real picture of the situation and this approach also prevents drop outs that typically occur during follow-up. It is well- known that hospitals have a high staff turnover rate, mainly among younger workers and the professional group "others". The population in our sample was young and this was an important factor in determining the best design for our research aims. The inclusion of biological measures to confirm the accuracy of self-reported smoking would have improved the reliability of the data. However, previous studies have shown that self-reports are an adequate form of classifying smokers in observational studies [60].

\section{Conclusion}

In conclusion, a long-term tobacco control strategywhich included sensitization campaigns, tobacco cessation training, cessation programs, and periodic monitoring and evaluation-in conjunction with two national smoke-free bans, helped to reduce smoking prevalence rates among hospital workers. However, convincing health care providers to become more involved in tobacco control is still a challenge. In addition to the array of tobacco control initiatives that organizations could undertake (such as education, cessation programs, and awareness campaigns), future actions to effectively decrease tobacco consumption and increase providers' involvement will depend on the commitment of public health departments, agencies, and governmental bodies. These should encourage and support health care providers, and especially to nurses, their engagement in tobacco control in order that they become part of the solution of the tobacco epidemic.

\section{Abbreviations \\ $\mathrm{Cl}$ : Confidence intervals; ENSH: ENSH-global network for tobacco-free health care services; ICO: Catalan institute of oncology; PR: Prevalence ratio; \\ SHS: Second-hand smoke; WHO FCTC: World health organization framework convention on tobacco control.}

\section{Competing interests}

The authors declare that they have no competing interests.

\section{Authors' contributions}

CM and EF conceptualized this study and led the manuscript. CM, MF, JMM and executed the analysis, and participated in the data interpretation. AR, $M B, P F, L A$ and XS coordinated the cross sectional surveys. All authors read, commented and approved the final version of this manuscript.

\section{Acknowledgments}

C Martinez was supported by the Spanish Government through a BAE grant (BA12/00074) to conduct postdoctoral research at the University of California San Francisco. The Tobacco Control Unit received support from the Instituto de Salud Carlos III (RD12/0036/0053) and the Directorate of Universities and Research, Government of Catalonia (2009SGR192).

\section{Author details}

${ }^{1}$ Tobacco Control Unit, Cancer Control and Prevention Programme, Institut Català d'Oncologia-ICO, Av. Granvia de L'Hospitalet 199-203, 08908 L'Hospitalet de Llobregat, Barcelona, Spain. ${ }^{2}$ Cancer Control and Prevention Group, Institut d'Investigació Biomèdica de Bellvitge-IDIBELL, Av. Granvia de L'Hospitalet 199-203, 08908 L'Hospitalet de Llobregat, Barcelona, Spain. ${ }^{3}$ Medicine and Health Sciences School, Universitat Internacional de Catalunya, C. Josep Trueta s/n, 08915 Sant Cugat del Valles, Barcelona, Spain. ${ }^{4}$ Biostatistic Unit, Department of Basic Sciences, School of Medicine and Health Sciences, Universitat Internacional de Catalunya, C. Josep Trueta s/n. 08915 Sant Cugat del Valles, Barcelona, Spain. ${ }^{5}$ Nursing Research Unit, Institut Català d'Oncologia-ICO, Av. Granvia de L'Hospitalet 199-203, 08908 L'Hospitalet de Llobregat (Barcelona), Spain, Barcelona, Spain. ${ }^{6}$ Addictions Unit, Institute of Neurosciences, Hospital Clínic de Barcelona - IDIBAPS, C. Villarroel 170, 08036 Barcelona, Spain. ${ }^{7}$ Department of Clinical Sciences, School of Medicine, Universitat de Barcelona, C. Feixa llarga s/n. 08907 L'Hospitalet del Llobregat, Barcelona, Spain. ${ }^{8}$ Department of Methodology for the Behavioural Sciences, University of Barcelona, Barcelona, Spain. 
Received: 28 July 2014 Accepted: 17 November 2014

Published: 27 November 2014

\section{References}

1. WHO Tobacco Free Initiative: 2012 global progress report on implementation of the WHO Framework Convention on Tobacco Control. Edited by WHO. Geneva: WHO; 2012. Available at: http://www.who. int/fctc/reporting/2012_global_progress_report_en.pdf.

2. Hyland A, Barnoya J, Corral JE: Smoke-free air policies: past, present and future. Tob Control 2012, 21(2):154-161.

3. Americans for Non Smokers' Rights. http://www.no-smoke.org/ goingsmokefree. php?id=499.

4. Callinan JE, Clarke A, Doherty K, Kelleher C: Legislative smoking bans for reducing secondhand smoke exposure, smoking prevalence and tobacco consumption. Cochrane Database Syst Rev 2010, 4, CD005992.

5. U.S. Department of Health and Human Services: Ending the Tobacco Epidemic: Progress Toward a Healthier. Washington: U.S: Department of Health and Human Services, Office of the Assistant Secretary for Health; 2012. Available: http://www.hhs.gov/ash/initiatives/tobacco/ tobaccoprogress2012.pdf.

6. WHO Framework Convention on Tobacco Control: Review of accreditation of nongovernmental organizations with observer status to the Conference of the Parties to the WHO Framework Convention on Tobacco Control. ; 2010. FCTC/ COP/4/22 Rev. 1

7. Tobacco free Kids: Smoke free laws. http://global.tobaccofreekids.org/en/ solutions/international_issues/smoke_free_laws/.

8. Martinez C, Martinez-Sanchez JM, Robinson G, Berther C, Fernandez E: Protection to Secondhand Smoke in the WHO European Region: an assessment of legislation. 2013. In press.

9. Gadomski AM, Stayton M, Krupa N, Jenkins P: Implementing a smoke-free medical campus: impact on inpatient and employee outcomes. $J$ Hosp Med 2010, 5(1):51-54.

10. Martinez C, Fu M, Martinez-Sanchez JM, Ballbe M, Puig M, Garcia M, Carabasa E, Salto E, Fernandez E: Tobacco control policies in hospitals before and after the implementation of a national smoking ban in Catalonia. Spain. BMC Public Health 2009, 9:160.

11. Ratschen E, Britton J, Doody GA, McNeill A: Smoke-free policy in acute mental health wards: avoiding the pitfalls. Gen Hosp Psychiatry 2009, 31(2):131-136.

12. Williams SC, Hafner JM, Morton DJ, Holm AL, Milberger SM, Koss RG, Loeb $J M$ : The adoption of smoke-free hospital campuses in the United States. Tob Control 2009, 18(6):451-458.

13. Fernandez E, Martinez C, Fu M, Martinez-Sanchez JM, Lopez MJ, Invernizzi G, Ouranou A, Dautzenberg B, Nebot M: Second-hand smoke exposure in a sample of European hospitals. Eur Respir J 2009, 34(1):111-116.

14. Sureda X, Fu M, Jose Lopez M, Martinez-Sanchez JM, Carabasa E, Salto E, Martinez C, Nebot M, Fernandez E: Second-hand smoke in hospitals in Catalonia (2009). A cross-sectional study measuring PM(2.5) and vapor-phase nicotine. Environ Res 2010, 110(8):750-755.

15. Martinez C, Garcia M, Mendez E, Peris M, Fernandez E: Barriers and challenges for tobacco control in a smoke-free hospital. Cancer Nurs 2008, 31(2):88-94.

16. Ratschen E, Britton J, McNeill A: Smoke-free hospitals - the English experience: results from a survey, interviews, and site visits. BMC Health Serv Res 2008, $8: 41$.

17. Knight J, Slattery C, Green S, Porter A, Valentine M, Wolfenden L: Smoke-free hospitals: an opportunity for public health. J Public Health (Oxf) 2008, 30(4):516.

18. Reid RD, Mullen KA, Slovinec D'Angelo ME, Aitken DA, Papadakis S, Haley PM, McLaughlin CA, Pipe AL: Smoking cessation for hospitalized smokers: an evaluation of the "Ottawa Model". Nicotine Tob Res 2010, 12(1):11-18.

19. Schultz $A S$, Finegan $B$, Nykiforuk $C l$, Kvern MA: A qualitative investigation of smoke-free policies on hospital property. CMAJ 2011, 183(18):E1334-E1344.

20. Shopik NA, Schultz AS, Nykiforuk Cl, Finegan BA, Kvern MA: Impact of smoke-free hospital grounds policies: patient experiences and perceptions. Health Policy 2012, 108(1):93-99.

21. LEY 28/2005: De 26 De Diciembre, de Medidas Sanitarias frente al tabaquismo y reguladora de la venta, el suministro, el consumo y la publicidad de los productos del tabaco, Health measures of the selling, use, consumption and publicity of tobacco products, Volume BOE Núm. 309 de 27 de diciembre; 2005.
22. Ley $42 / 2010$, de 30 de diciembre, por la que se modifica la Ley $28 / 2005$, de 26 de diciembre, de medidas sanitarias frente al tabaquismo y reguladora de la venta, el suministro, el consumo y la publicidad de los productos del tabaco: Law that modifies Lay 28/2005 of health measures of the selling, use, consumption and publicity of tobacco products, Volume BOE Núm. 318; 2010.

23. Batlle E, Boixet M, Agudo A, Almirall J, Salvador T: Tobacco prevention in hospitals: long-term follow-up of a smoking control programme. $\mathrm{Br} J$ Addict 1991, 86(6):709-717.

24. Garcia M, Mendez E, Martinez C, Peris M, Fernandez E: Implementing and complying with the Smoke-free Hospitals Project in Catalonia. Spain. Eur $J$ Cancer Prev 2006, 15(5):446-452.

25. ENSH: European Network for the Smoke free Hospitals. Paris: European Network for Smoke-free Hospitals and Health Care Services. 2009. Available at: http://www.ensh.eu/most-downloaded.php?id=34.

26. Martinez C, Martinez-Sanchez JM, Ballbe M, Nieva G, Fu M, Puig M, Carabasa E, Sanchez-Garcia JM, Salto E, Fernandez E, Tobacco Cessation Program Project Coordinators: Smoking cessation in hospital workers: effectiveness of a coordinated program in 33 hospitals in Catalonia (Spain). Cancer Nurs 2012, 35(5):327-336.

27. Martinez C, Garcia M: Evaluation of the degree of implementation of tobacco control interventions in the Catalan Network of Smoke-Free Hospitals. Enferm Clin 2007, 17(4):177-185.

28. Fernandez Ruiz ML, Sanchez Bayle M: Evolution of the prevalence of smoking among female physicians and nurses in the Autonomous Community of Madrid, Spain. Gac Sanit 2003, 17(1):5-10.

29. Precioso J, Lopez MJ, Calheiros JM, Macedo M, Ariza C, Sanchez F, Schiaffino A, Fernandez E, Nebot M: Indoor air pollution caused by cigarette smoke in public places in Portugal. Rev Saude Publica 2007, 41(5):808-813.

30. Ravara SB, Calheiros JM, Aguiar P, Barata LT: Smoking behaviour predicts tobacco control attitudes in a high smoking prevalence hospital: a cross-sectional study in a Portuguese teaching hospital prior to the national smoking ban. BMC Public Health 2011, 11:720.

31. Departament de Salut. Generalitat de Catalunya: Enquesta de Salut de Catalunya 2006; 2006.

32. Hughes JR, Keely JP, Niaura RS, Ossip-Klein DJ, Richmond RL, Swan GE: Measures of abstinence in clinical trials: issues and recommendations. Nicotine Tob Res 2003, 5(1):13-25.

33. Prochaska JO, DiClemente CC, Norcross JC: In search of how people change. Applications to addictive behaviors. Am Psychol 1992, 47(9):1102-1114.

34. Fichtenberg CM, Glantz SA: Effect of smoke-free workplaces on smoking behaviour: systematic review. BMJ 2002, 325(7357):188.

35. Longo DR, Brownson RC, Johnson JC, Hewett JE, Kruse RL, Novotny TE, Logan RA: Hospital smoking bans and employee smoking behavior: Results of a national survey. JAMA 1996, 275(16):1252-1257.

36. Longo DR, Feldman MM, Kruse RL, Brownson RC, Petroski GF, Hewett JE: Implementing smoking bans in American hospitals: results of a national survey. Tob Control 1998, 7(1):47-55.

37. Servei Català de la Salut: Enquesta de Salut de Catalunya 2002; 2002.

38. Servei Català de la Salut: Enquesta consum tabac 2011. In Servei Català de la Salut. Departament de Sanitat i Seguretat Social. Generalitat de Catalunya; 2012.

39. WHO Tobacco Free Iniciative: The role of health professionals in tobacco control. Edited by WHO. Ginebra; 2005. Anonymous.

40. Smith DR, Leggat PA: An international review of tobacco smoking in the medical profession: 1974-2004. BMC Public Health 2007, 7:115.

41. Fitzpatrick P, Gilroy I, Doherty K, Corradino D, Daly L, Clarke A, Kelleher CC: Implementation of a campus-wide Irish hospital smoking ban in 2009: prevalence and attitudinal trends among staff and patients in lead up. Health Promot Int 2009, 24(3):211-222.

42. Tong EK, Strouse R, Hall J, Kovac M, Schroeder SA: National survey of U.S. health professionals' smoking prevalence, cessation practices, and beliefs. Nicotine Tob Res 2010, 12(7):724-733.

43. Gruer L, Tursan d'Espaignet E, Haw S, Fernandez E, Mackay J: Smoke-free legislation: global reach, impact and remaining challenges. Public Health 2012, 126(3):227-229.

44. Rogers EM: Diffusion of Innovations. 5th edition. New York: Free Press; 2003.

45. Hung DY, Leidig R, Shelley DR: What's in a setting? Influence of organizational culture on provider adherence to clinical guidelines for treating tobacco use. Health Care Manage Rev 2014, 39(2):154-63.

46. Britton J, Bogdanovica I: Tobacco control efforts in Europe. Lancet 2013, 381(9877):1588-1595. 
47. Freund M, Campbell E, Paul C, Sakrouge R, McElduff P, Walsh RA, Wiggers J, Knight J, Girgis A: Increasing smoking cessation care provision in hospitals: a meta-analysis of intervention effect. Nicotine Tob Res 2009, 11(6):650-662.

48. Fernandez E, Martinez C, Alonso B, Chalom D, Dumont J, Gunning M, Mihaltan F, O'Riordan A, Rustler C: Tobacco-Free Hospital Campuses in Europe. http://tobaccocontrol.bmi.com/content/18/6/451/reply\#content-block.

49. Ballbe M, Nieva G, Mondon S, Pinet C, Bruguera E, Salto E, Fernandez E, Gual A, Smoking and Mental Health Group: Smoke-free policies in psychiatric services: identification of unmet needs. Tob Control 2012, 21(6):549-554.

50. Campbell S, Pieters K, Mullen KA, Reece R, Reid RD: Examining sustainability in a hospital setting: case of smoking cessation. Implement Sci 2011, 6:108.

51. Knudsen HK, Muilenburg J, Eby LT: Sustainment of smoking cessation programs in substance use disorder treatment organizations. Nicotine Tob Res 2013, 15(6):1060-8.

52. Warner KE, Burns DM: Hardening and the hard-core smoker: concepts, evidence, and implications. Nicotine Tob Res 2003, 5(1):37-48.

53. Ravara SB, Castelo-Branco M, Aguiar P, Calheiros JM: Smoking behaviour trends among Portuguese physicians: are they role models? A conference-based survey. Public Health 2014, 128(1):105-109.

54. Hovengen R, Nordhagen R: Occasional smoking-an increasing problem. Tidsskr Nor Laegeforen 2004, 124(24):3222-3223.

55. Bodner ME, Miller WC, Rhodes RE, Dean E: Smoking cessation and counseling: knowledge and views of Canadian physical therapists. Phys Ther 2011, 91(7):1051-1062.

56. Sarna L, Wewers ME, Brown JK, Lillington L, Brecht ML: Barriers to tobacco cessation in clinical practice: report from a National Survey of Oncology Nurses. Nurs Outlook 2001, 49(4):166-172.

57. Sarna LP, Brown JK, Lillington L, Rose M, Wewers ME, Brecht ML: Tobacco interventions by oncology nurses in clinical practice: report from a national survey. Cancer 2000, 89(4):881-889.

58. Mackay J: Implementing tobacco control policies. Br Med Bull 2012, 102:5-16.

59. Ramos MC, Vinagre S, Cardoso MF: Knowledge, behavior and ethical responsibility of health professionals with regard to smoking. Rev Port Cardiol 2010, 29(6):923-946.

60. Connor Gorber S, Schofield-Hurwitz S, Hardt J, Levasseur G, Tremblay M: The accuracy of self-reported smoking: a systematic review of the relationship between self-reported and cotinine-assessed smoking status. Nicotine Tob Res 2009, 11(1):12-24.

doi:10.1186/1471-2458-14-1228

Cite this article as: Martínez et al:: Impact of a long-term tobacco-free policy at a comprehensive cancer center: a series of cross-sectional surveys. BMC Public Health 2014 14:1228.

\section{Submit your next manuscript to BioMed Central and take full advantage of:}

- Convenient online submission

- Thorough peer review

- No space constraints or color figure charges

- Immediate publication on acceptance

- Inclusion in PubMed, CAS, Scopus and Google Scholar

- Research which is freely available for redistribution 